\title{
Use of Gelatin-Thrombin Matrix Hemostatic Sealant in Cranial Neurosurgery
}

\author{
Ingo FISS, Marco DANNE, and Ruediger STENDEL \\ Department of Neurosurgery, Charite-University Medicine Berlin, Campus Benjamin Franklin, \\ Berlin, Germany
}

\begin{abstract}
The present study evaluated the hemostatic efficacy and handling of gelatin-thrombin matrix hemostatic sealant during intracranial procedures. A retrospective analysis of 478 consecutive patients undergoing intracranial procedures identified seven patients with acute intense or persistent intraoperative bleeding which could not be arrested in time by standard hemostatic methods. The efficacy of gelatinthrombin matrix was assessed by determining bleeding severity before and after application, time to hemostasis, amount of gelatin-thrombin matrix necessary, need for additional hemostatic measures, and need for reoperation to control hemorrhage. Immediate hemostasis was achieved in five of seven patients. Two of these five patients had abnormal clotting parameters. Cessation of bleeding was achieved by additionally applying either fibrinogen or gelatin sponge to the bleeding site in the other two patients. No complications attributable to gelatin-thrombin matrix use were recorded. The gelatinthrombin matrix was ready to use within 1 minute in every case. Gelatin-thrombin matrix appears to be an effective, easy-to-use, and readily available hemostatic agent for cranial neurosurgery. Combination with fibrinogen is recommended in special situations.
\end{abstract}

Key words: hemostasis, bleeding, thrombin, fibrinogen, disseminated intravascular coagulation, neurosurgery

\section{Introduction}

Immediate hemostasis is extremely important in brain surgery, because even small amounts of blood within the brain parenchyma may lead to permanent neurological damage or even death. Micro-neurosurgical interventions in the brain require clear fields of vision, so continuous bleeding may obscure the target structures with the potential for tissue damage. Patients with intracranial lesions requiring acute surgery frequently have associated disturbances of plasmatic and/or thrombocytic coagulation caused by medication such as acetylsalicylic acid, warfarin, or phenprocoumon. ${ }^{10,15,22)}$ Such coagulation disorders are often impossible to detect or to correct rapidly in emergencies. Mechanical methods of hemostasis such as direct pressure and ligation have very limited uses in brain surgery. Numerous hemostatic agents with different mechanisms of action are available (Table 1), but there is a need for a fast and safe hemostatic method that is effective even in patients with coagulation disorders.

Received August 17, 2006;

Accepted June 25, 2007
Gelatin-thrombin matrix hemostatic sealant is a gelatin matrix consisting of cross-linked bovine-derived gelatin granules and a bovine-derived thrombin component (since March 2005 a human thrombin component has been available). The gelatinthrombin matrix can be prepared immediately before use, ${ }^{30)}$ as a highly viscous gel that can be applied using a syringe with a special applicator. The gelatin-thrombin matrix is hydrophilic, so adheres well to wet tissue in contrast to fibrin glue, acrylic acid, or gelatin-resorcin-formaldehyde, which need a dry surface. The large amounts of thrombin concentrated on the large surface area of the gelatin matrix and contact activation by gelatin lead to fast hemostasis. ${ }^{1)}$ This effect is supported by the moderate swelling (about 10-20\%) of the gelatin-thrombin matrix following contact with blood or other body fluids. ${ }^{1)}$ This gelatin-thrombin matrix is useful in cardiac, ${ }^{24,25)}$ spinal, ${ }^{29)}$ maxillofacial and plastic facial, ${ }^{11,12,28)}$ rhinologic, ${ }^{2,4)}$ and urologic ${ }^{31,34)}$ surgery. However, little is known about its use in brain surgery except in transsphenoidal pituitary surgery, in which the safety and biocompatibility were comparable with hemostatic agents currently in use. ${ }^{7)}$ 
Table 1 Contents and mechanism of action of hemostatic agents used in neurosurgery

\begin{tabular}{|c|c|c|}
\hline Material & Mechanism of action & Remarks \\
\hline $\begin{array}{l}\text { Cellulose } \\
\text { Surgicel }^{\mathrm{a}} \\
\text { Oxycel }^{\mathrm{b}} \\
\text { Tabotamp }^{\mathrm{a}}\end{array}$ & $\begin{array}{l}\text { contact activation of clotting cascade, } \\
\text { swelling when saturated with blood }\end{array}$ & $\begin{array}{l}\text { Surgicel fibrillar can be peeled off in desired amounts, } \\
\text { suction \& cauterization possible directly through } \\
\text { material }^{32)}\end{array}$ \\
\hline $\begin{array}{l}\text { Gelatin } \\
\text { Gelfoam } \\
\text { Surgifoam }^{\mathrm{a}} \\
\text { Surgiflo }^{\mathrm{a}}\end{array}$ & contact activation of clotting cascade & $\begin{array}{l}\text { Gelfoam: should be removed after hemostasis (swelling on } \\
\text { absorbing fluids is possible) }{ }^{19)} \text {; } \\
\text { Surgifoam: should be removed after hemostasis, can be } \\
\text { easily molded onto the contours of the bleeding surface } \\
\text { (swelling on absorbing fluids is possible) } \\
\text { Surgiflo: flowable hemostat which allows customization of } \\
\text { its consistency }{ }^{35)}\end{array}$ \\
\hline $\begin{array}{l}\text { Collagen } \\
\text { Avitene } \\
\text { Actifoam }^{\mathrm{e}} \\
\text { Helistat }^{\mathrm{f}} \\
\text { Instat }^{\mathrm{a}}\end{array}$ & $\begin{array}{l}\text { contact activation and promotion of } \\
\text { platelet aggregation to induce the } \\
\text { clotting cascade }\end{array}$ & $\begin{array}{l}\text { agents need functioning coagulation cascade and full } \\
\text { spectrum of clotting factors }\end{array}$ \\
\hline $\begin{array}{l}\text { Thrombin } \\
\text { Thrombin-JMIg }\end{array}$ & $\begin{array}{l}\text { direct conversion of fibrinogen to } \\
\text { fibrin }\end{array}$ & $\begin{array}{l}\text { Thrombin-JMI: may be used in conjunction with for } \\
\text { example an absorbable gelatin sponge with thrombin, has } \\
\text { been chromatographically purified, }{ }^{16)} \text { needs circulating } \\
\text { fibrinogen }\end{array}$ \\
\hline $\begin{array}{l}\text { Fibrin glue } \\
\text { Tissucol }^{\mathrm{d}} \\
\text { Tisseel }^{\mathrm{d}}\end{array}$ & $\begin{array}{l}\text { generation of a clot is promoted by } \\
\text { mixed fibrinogen, thrombin, and } \\
\text { factor XIII delivered via a double- } \\
\text { barrel syringe; also includes aproti- } \\
\text { nin (to slow down fibrinolysis) }\end{array}$ & $\begin{array}{l}\text { Tissucol: should not be used to glue nerve anastomosis } \\
\text { since fibrosis formation due to the high content of } \\
\text { aprotinin cannot be excluded }{ }^{25} \text { ) }\end{array}$ \\
\hline $\begin{array}{l}\text { Aldehyde glues } \\
\text { Bioglue }^{\mathrm{h}}\end{array}$ & $\begin{array}{l}\text { bovine serum albumin and glutaralde- } \\
\text { hyde cross-link with body proteins to } \\
\text { form a stable adhesive }\end{array}$ & $\begin{array}{l}\text { not recommended in contact with nerve or heart valve } \\
\text { tissue and to correct problems with blood vessels in the } \\
\text { brain, has space-occupying properties }\end{array}$ \\
\hline $\begin{array}{l}\text { Polysaccharide } \\
\text { Arista } \mathrm{HM}^{\mathrm{i}}\end{array}$ & $\begin{array}{l}\text { particles act as molecular sieve that act } \\
\text { to rapidly dehydrate blood and } \\
\text { concentrate clotting proteins, red } \\
\text { blood cells, and platelets to promote } \\
\text { clot formation }\end{array}$ & $\begin{array}{l}\text { flowable microporous particles from purified plant starch, } \\
\text { only available in powder form }{ }^{21)}\end{array}$ \\
\hline $\begin{array}{l}\text { Gelatin-thrombin matrix } \\
\text { FloSeal }\end{array}$ & $\begin{array}{l}\text { hemostatic effect is a combination of } \\
\text { thrombin on a large surface, contact } \\
\text { activation of clotting cascade by } \\
\text { gelatin and to a lesser extent swelling } \\
\text { following contact with blood }\end{array}$ & $\begin{array}{l}\text { human thrombin component is available, ready-to-use } \\
\text { within } 1 \mathrm{~min} \text {, works on wet surface }\end{array}$ \\
\hline
\end{tabular}

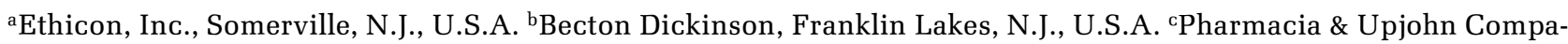
ny, Kalamazoo, Mich., U.S.A. ${ }^{\mathrm{d} B a x t e r}$ Biosurgery AG, Vienna, Austria. ${ }^{\mathrm{e}}$ C. R. Bard, Inc., Murray Hill, N.J., U.S.A. ${ }^{\mathrm{f}}$ Integra Life Sciences, Inc., Plainsboro, N.J., U.S.A. ${ }^{\mathrm{g}}$ King Pharmaceuticals, Inc., Bristol, Tenn., U.S.A. ${ }^{\mathrm{h} C r y o l i f e, ~ I n c ., ~}$ Kennesaw, Ga., U.S.A. 'ंMedafor, Inc., Minneapolis, Minn., U.S.A. 'Baxter Healthcare Corporation, Fremont, Calif., U.S.A.

The present study evaluated the hemostatic efficacy and handling of gelatin-thrombin matrix in brain surgery.

\section{Materials and Methods}

In this retrospective analysis, patients were included who underwent intracranial neurosurgical procedures with acute intense or persistent bleeding during brain surgery which could not be arrested by standard methods of hemostasis (bipolar coagulation, irrigation, use of cellulose and collagen sponge, compression with cottonoid patties), or these methods could not be applied. The only contraindication was an active local infection. Seven out of 478 (1.5\%) consecutive patients ( 3 male, 4 female; mean age $57.7 \pm 23.4$ years) could be identified which met the inclusion criteria (Table 2).
The gelatin-thrombin matrix (FloSeal ${ }^{\circledR}$ Matrix; Baxter Healthcare Corporation, Fremont, Calif., U.S.A.) was delivered to the site of bleeding via a single-barrel syringe and a special applicator tip according to the manufacturer's instructions. The source and type of bleeding (arterial, venous, or generalized venous oozing), time to bleeding control, application technique, quantity of gelatinthrombin matrix used, and complications were recorded.

\section{Results}

The types of bleeding were classified as arterial in two patients, generalized venous oozing in three, and venous bleeding from the superior sagittal sinus in two (Table 2). The time to prepare gelatin-thrombin matrix ready-to-use did not exceed 1 minute. 
Table 2 Characteristics of patients treated with gelatin-thrombin matrix hemostatic agent

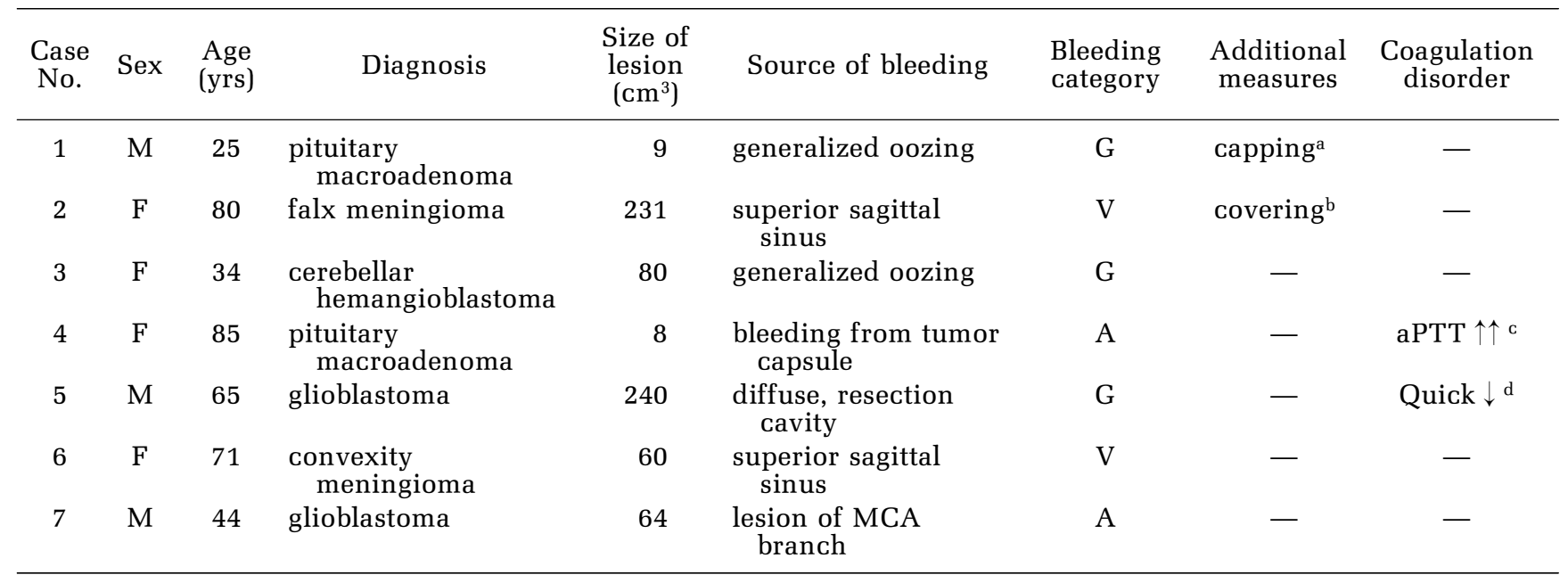

${ }^{a}$ Capping with fibrinogen component of fibrin glue (Tissucol ${ }^{\mathbb{R}}$ ). ${ }^{\mathrm{b}}$ Covering with absorbable gelatin sponge

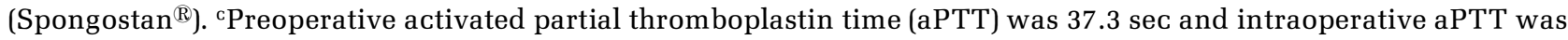
125.9 sec. 'Intraoperative prothrombin time (Quick's value) was 57\%. A: arterial bleeding, G: generalized oozing, MCA: middle cerebral artery, V: venous bleeding.

Effective hemostasis was achieved no later than 240 seconds after initial application of gelatinthrombin matrix in all patients except two (Table 2). The bleeding was finally stopped by adding the fibrinogen component of fibrin glue (Tissucol ${ }^{\mathbb{R}}$; Baxter AG, Vienna, Austria) in one patient (Case 1). Venous bleeding from the superior sagittal sinus was stopped by adding absorbable gelatin sponge (Spongostan ${ }^{\mathbb{R}}$; Johnson \& Johnson, Inc., New Brunswick, N.J., U.S.A.) to fix the gelatin-thrombin matrix and prevent displacement due to the strong bleeding in the other patient (Case 2).

No local and/or systemic complications, embolisms, or vessel occlusions were observed. None of the patients developed allergic reactions, or local or generalized infections associated with the gelatinthrombin matrix. There was no morbidity and no patient required reoperation. The gelatin-thrombin matrix was easy to apply in all cases using the applicator tip of the kit.

Follow-up imaging (computed tomography or magnetic resonance imaging) was performed on days 0 to 23 after operation and was available in five of the seven patients. Normal postoperative conditions were found without signs of inflammation, perifocal edema, or scar formation attributable to the gelatin-thrombin matrix.

Follow-up neurological examination was performed on day 1 postoperatively and at discharge. Three patients were additionally evaluated at 6,7 , or 24 months after the operation. All identified neurological deficits were either known potential compli- cations of the type of operation performed or were already present prior to the operation (temporary hemiparesis in 2 patients, mild pre-existing hemiparesis in 2 patients).

\section{Discussion}

Gelatin-thrombin matrix was first approved by the United States Food and Drug Administration in 1999 based on safety and effectiveness data from a multicenter, multispecialty, prospective, randomized clinical trial involving 309 patients undergoing cardiac, vascular, or spinal surgery. ${ }^{29)}$ The most common adverse events during and after the application were anemia, atrial fibrillation, infection, and hemorrhage. None of the adverse events reported in more than $1 \%$ of patients were judged to be "probably related" to the use of gelatin-thrombin matrix. The initially excluded neurosurgical procedures were added to the "Indications for Use" in April 2001 (U.S. Food and Drug Administration, Center for Devices and Radiological Health Premarket Approval Decision for August 2001. P990009/S009, 8/10/01, Real-Time. Available from: http://www.fda.gov/cdrh/pma/pmaaug01.html).

The gelatin-thrombin matrix consists of bovine gelatin which has an extremely low immunogenicity. There are no reports in the literature of any allergic reactions to the gelatin-thrombin matrix. During its safety history, more than 1.5 million applications were counted in all surgical specialties except ophthalmology. During this period, 2-3 suspected 
local allergic manifestations, rather than systemic reactions, were reported. This corresponds to an incidence of $0.0002 \%$ (personal communication, Baxter Biosurgery AG: FloSeal ${ }^{\mathbb{R}}$ Safety Considerations. Vienna, Austria, 2007). However, in case of serious systemic reactions, airway patency should be immediately assessed. The established primary drug treatments for anaphylaxis are epinephrine and $\mathrm{H}_{1}$-antihistamines, whereas corticosteroids are mainly effective in preventing biphasic reactions. ${ }^{9)}$

The source of the gelatin for the gelatin-thrombin matrix as well as the manufacturing process of the gelatin granules is certified according to the bovine spongiform encephalopathy safety regulations in the U.S.A. and the European Union (EU), which has the strongest safety requirements in regard to Creutzfeldt-Jacob disease transmission risk. The safety concerning bovine spongiform encephalopathy (BSE) of the gelatin granules has recently been recertified based on the new EU regulation for bovine derived materials as being BSE safe (personal communication, Baxter Biosurgery AG: FloSeal ${ }^{\mathbb{R}}$ Safety Considerations. Vienna, Austria, 2007).

Use of gelatin-thrombin matrix in a rat fasciocutaneous free flap model did not reveal any adverse effects on survival. ${ }^{11,28)}$ A brain implantation study in rats indicated that intracerebral implantation of gelatin-thrombin matrix does not result in hydrocephalus or mortality. ${ }^{1)}$ Furthermore, the inflammatory reaction in the brain was similar, and definitely not worse than, the reaction to other hemostatic agents based on cellulose, gelatin, and collagen. The median time to biodegradation was 30 days for gelatin-thrombin matrix versus 60 days for cellulose, and more than 90 days for gelatin, gelatin plus thrombin, and collagen agents. Swelling following exposure to normal saline was only $11 \%$ for gelatin-thrombin matrix compared to $260 \%$ for collagen, $320 \%$ for gelatin, and $135 \%$ for cellulose agents. The moderate swelling of gelatin-thrombin matrix following contact with blood or other fluids is highly beneficial and may be considered essential for use in brain surgery.

Evaluation of the biocompatibility of gelatinthrombin matrix in a rabbit model of splenic injury and bleeding ${ }^{1)}$ found no gross evidence of the material after 14 days, and no postoperative adhesions. The observed acute inflammatory response and fibrosis was typical of the normal wound healing process of the spleen following injury.

Clinical evaluation of gelatin-thrombin matrix for use in endoscopic sinus surgery showed clear trends towards increased granulation tissue and adhesion formation compared to the patients treated with thrombin-soaked gelatin foam. ${ }^{5)}$ However, gelatin- thrombin matrix was associated with a high degree of patient comfort and effective hemostasis after endoscopic sinus surgery. Gelatin-thrombin matrix appeared to be associated with scar tissue formation and incorporation into the recovering mucosa at 1year follow up, suggesting that increased requirement for postoperative care. This effect seems to be associated with this specific location, and the mucosa is probably important in the formation of such scar tissue.

The preclinical and clinical testing demonstrated reasonable assurance of the safety and effectiveness of gelatin-thrombin matrix for approved indications. ${ }^{25,29)}$ This seems not to be true for other hemostatic agents used to control persistent bleeding. For example, some types of collagen-based agents can induce local inflammatory responses. ${ }^{36)}$

In the present study, one patient suffered persistent bleeding after gelatin-thrombin matrix administration, so fibrin glue was applied onto the hemostatic matrix, after which the hemorrhage ceased. The brain has a vast supply of tissue factor (thromboplastin), which is the most potent trigger of coagulation known. ${ }^{18)}$ Hypothetically, the local consumption of clotting factors may be so excessive in some intraoperative scenarios that uncontrolled bleeding can occur - a "localized disseminated coagulation." ${ }^{27)}$ Furthermore, the brain generally has only low levels of fibrinolytic activity apart from the pituitary gland ${ }^{33)}$ and the meninges. ${ }^{13,14,26)}$ These factors may explain the present success in achieving hemostasis by adding fibrinogen to gelatin-thrombin matrix. Factor XIII also present in fibrin glue causes the fibrin to crosslink, which gives the coagulum additional resilience.

A controlled study in a porcine model comparing fibrin glue with a combination of gelatin-thrombin matrix and fibrin glue for treating vascular and collecting-system injury during partial nephrectomy suggested that fibrin glue is not adequate for either hemostasis or management of major collectingsystem injury. ${ }^{17)}$ Gelatin-thrombin matrix capped with fibrin glue appeared sufficient to control major vascular and collecting-system injuries without adjunctive surgical measures.

Apparently gelatin-thrombin matrix requires fibrinogen to develop its hemostatic potential. The physiological level of fibrinogen in plasma is approximately $1.5 \mathrm{mg} / \mathrm{ml}$ (von Clauss coagulation micro-method). ${ }^{6}$ The fibrinogen concentration in fibrin glue is $70-110 \mathrm{mg} / \mathrm{ml}$, which is about 45 to 70 fold that in serum. ${ }^{3)}$ Therefore, we suggest that the initial attempt to stop bleeding should be made with a single unit of gelatin-thrombin matrix. If adequate hemostasis is not achieved, capping with fibrin glue 
might seem more useful than applying a second load of gelatin-thrombin matrix, thus facilitating activation of the fibrinogen component to overcome intraoperative dys- or afibrinogenemia. Absence of fibrinogen is a special situation usually confined to local intraoperative problems. ${ }^{27}$ The incidence of systemic fibrinogen deficiency in the Caucasian population is reported to be as low as $1: 1,000,000 .^{23)}$

Thrombin only acts at the end of the clotting cascade, so its action is less susceptible to coagulopathies due to clotting factor deficiencies or platelet malfunction. However, such coagulopathies can compromise the activity of other hemostatic agents based on collagen, gelatin, or oxidized cellulose. The plasma concentration of prothrombin is 1-2 $\mathrm{nmol} / \mathrm{ml}$, which completely converted yields 100-200 IU thrombin/ml. ${ }^{20}$ The $5 \mathrm{ml}$ syringe of gelatin-thrombin matrix (standard kit) contains 5000 IU of thrombin. ${ }^{30)}$

The present study also observed inadequate hemostasis in a patient during extirpation of a meningioma, when bleeding occurred from a longitudinal tear along the superior sagittal sinus. Hemostasis was achieved by additional application of an absorbable gelatin sponge. We assume that the failure to achieve hemostasis by gelatin-thrombin matrix was due to the configuration of the bleeding lesion. The gelatin-thrombin matrix, which was applied as a thin film, did not have adequate coherence and had to be supported and held in place by the gelatin sponge. In this case, inadequate hemostasis was a problem of application rather than of efficacy.

The present study identified no adverse events, especially no signs of local infection, in the patients. Other gelatin-based hemostatic agents are known to act as potential centers for infection and abscess formation and promote bacterial growth. ${ }^{1)}$ Evaluation of follow-up cranial neuroimaging examinations did not reveal any abnormal findings associated with the application of gelatin-thrombin matrix, as reported previously. ${ }^{25,29)}$

The major question that should be addressed concerns the most suitable strategy to deal with intracranial bleeding during operations: should we continue to rely on the well-known methods (gentle pressure, suction cautery, bipolar cautery, gelfoam sponges etc.) to prevent or arrest bleeding? These methods bear the risk of tissue destruction with deleterious sequelae. The alternative in special situations is to achieve rapid hemostasis by using a fast and reliably acting local hemostatic sealant.

The present study suggests that safe and fast management of venous and arterial bleedings during brain surgery can be achieved by application of gelatin-thrombin matrix hemostatic agent. The gelatin-thrombin matrix is easier to apply in regions which are difficult to reach, and the consistency provides more tissue contact than a thrombin-soaked gelatin sponge. Reinforcement with fibrin glue is better than applying more matrix in cases of vigorous bleeding due to presumed local disseminated intravascular coagulation.

\section{References}

1) Bak JB, Singh A, Shekarriz B: Use of gelatin matrix tissue sealant as an effective hemostatic agent during laparoscopic partial nephrectomy. J Urol 171: 780-782, 2004

2) Baumann A, Caversaccio $M$ : Hemostasis in endoscopic sinus surgery using a specific gelatinthrombin based agent (FloSeal). Rhinology 41: 244-249, 2003

3) Buchta C, Hedrich HC, Macher M, Höcker P, Redl H: Biochemical characterization of autologous fibrin sealants produced by CryoSeal $^{\circledR}$ and Vivostat ${ }^{\circledR}$ in comparison to the homologous fibrin sealant product Tissucol/Tisseel ${ }^{\circledR}$. Biomaterials 26: 6233-6241, 2005

4) Chandra RK, Conley DB, Haines GK, Kern RC: Longterm effects of FloSeal packing after endoscopic sinus surgery. Am J Rhinol 19: 240-243, 2005

5) Chandra RK, Conley DB, Kern RC: The effect of FloSeal on mucosal healing after endoscopic sinus surgery: a comparison with thrombin-soaked gelatin foam. Am J Rhinol 17: 51-55, 2003

6) Destaing F, Duzer A, Ferrand B: Determination of fibrinogen by the Von Clauss coagulation micromethod. Pathol Biol (Paris) 8: 1615-1621, 1960

7) Ellegala DB, Maartens NF, Laws ER: Use of FloSeal hemostatic sealant in transsphenoidal pituitary surgery: technical note. Neurosurgery 51: 513-516, 2002

8) Esposito F, Dusick JR, Fatemi N, Kelly DF: Graded repair of cranial base defects and cerebrospinal fluid leaks in transsphenoidal surgery. Neurosurgery 60 Suppl 2: 295-303, 2006

9) Evans C, Tippins E: Emergency treatment of anaphylaxis. Accid Emerg Nurs 13: 232-237, 2005

10) Heesen $M$, Winking $M$, Kemkes-Matthes $B$, Deinsberger W, Dietrich GV, Matthes KJ, Hempelmann G: What the neurosurgeon needs to know about the coagulation system. Surg Neurol 47: 32-34, 1997

11) Jorgensen S, Bascom DA, Partsafas A, Wax MK: The effect of 2 sealants (FloSeal and Tisseel) on fasciocutaneous flap revascularization. Arch Facial Plast Surg 5: 399-402, 2003

12) Kaushik V, Tahery J, Malik TH, Jones PH: New surgical adjuncts in the treatment of rhinophyma: the microdebrider and FloSeal. J Laryngol Otol 117: 551-552, 2003

13) Kraus H: [Fibrinolytic activity of brain tumors and treatment of bleeding diathesis]. Schweiz Arch Neurol Neurochir Psychiatr 108: 27-31, 1971 (Ger)

14) Lambert CJ, Marengo-Rowe AJ, Leveson JE, Green 
RH, Thiele JP, Geisler GF, Adam M, Mitchel BF: The treatment of postperfusion bleeding using epsilonaminocaproic acid, cryoprecipitate, fresh-frozen plasma, and protamine sulfate. Ann Thorac Surg 28: 440-444, 1979

15) Lapointe LA, Von Rueden KT: Coagulopathies in trauma patients. AACN Clin Issues 13: 192-203, 2002

16) Lawson JH: The clinical use and immunologic impact of thrombin in surgery. Semin Thromb Hemost 32 Suppl 1: 98-110, 2006

17) L'Esperance JO, Sung JC, Marguet CG, Maloney ME, Springhart WP, Preminger GM, Albala DM: Controlled survival study of the effects of Tisseel or a combination of FloSeal and Tisseel on major vascular injury and major collecting-system injury during partial nephrectomy in a porcine model. J Endourol 19: 1114-1121, 2005

18) Losche W: Platelets and tissue factor. Platelets 16: 313-319, 2005

19) Lubaroff DM, Konety B, Link BK, Ratliff TL, Madsen T, Shannon M, Ecklund D, Williams RD: Clinical protocol: phase I study of an adenovirus/prostatespecific antigen vaccine in men with metastatic prostate cancer. Hum Gene Ther 17: 220-229, 2006

20) McDuffie FC, Giffin C, Niedringhaus R, Mann KG, Owen CA, Bowie EJ, Peterson J, Clark G, Hunder GG: Prothrombin, thrombin and prothrombin fragments in plasma of normal individuals and of patients with laboratory evidence of disseminated intravascular coagulation. Thromb Res 16: 759-773, 1979

21) Murat FJL, Ereth MH, Dong Y, Piedra MP, Gettman MT: Evaluation of microporous polysaccharide hemispheres as a novel hemostatic agent in open partial nephrectomy: favourable experimental results in the porcine model. J Urol 172: 1119-1122, 2004

22) Muskett A, Barber WH, Lineaweaver WC: The Plastic surgeon's guide to drugs affecting hemostasis. Ann Plast Surg 54: 570-576, 2005

23) Oldenburg J, Hartfelder HJ: [Blood coagulation and hemorrhagic diathesis]. Pharm Unserer Zeit 35: 20-28, 2006 (Ger)

24) Oz MC, Cosgrove DM, Badduke BR, Hill JD, Flannery MR, Palumbo R, Topic N: Controlled clinical trial of a novel hemostatic agent in cardiac surgery. The Fusion Matrix Study Group. Ann Thorac Surg 69: 1376-1382, 2000

25) Oz MC, Rondinone JF, Shargill NS: FloSeal Matrix: new generation topical hemostatic sealant. J Card Surg 18: 486-493, 2003
26) Palmer JD, Francis DA, Francis JL: Meningioma-induced fibrinolysis. J Neurol Neurosurg Psychiatry 57: 388, 1994 (abstract)

27) Palmer JD, Francis JL, Pickard JD, Iannotti F: The efficacy and safety of aprotinin for hemostasis during intracranial surgery. J Neurosurg 98: 1208-1216, 2003

28) Partsafas AW, Bascom DA, Jorgensen SA, Wax MK: Effects of Tisseel and FloSeal on primary ischemic time in a rat fasciocutaneous free flap model. Laryngoscope 114: 301-304, 2004

29) Renkens KL Jr, Paynor TD, Leipzig TJ, Feuer H, Morone MA, Koers JM, Lawson KJ, Lentz R, Shuey H, Conaway GL, Andersson GB, An HS, Hickey M, Rondinone JF, Shargill NS: A multicenter, prospective, randomized trial evaluating a new hemostatic agent for spinal surgery. Spine 26: 1645-1650, 2001

30) Reuthebuch O, Lachat ML, Vogt P, Schurr U, Turina M: FloSeal: a new hemostyptic agent in peripheral vascular surgery. Vasa 29: 204-206, 2000

31) Richter F, Tullmann ME, Turk I, Deger S, Roigas J, Wille A, Schnorr D: [Improvement of hemostasis in laparoscopic and open partial nephrectomy with gelatin thrombin matrix (FloSeal)]. Urologe A 42: 338-346, 2003 (Ger, with Eng abstract)

32) Sabel M, Stummer W: The use of local agents: Surgicel and Surgifoam. Eur Spine J 13 Suppl 1: S97-S101, 2004

33) Tice DA, Reed GE, Clauss RH: Hemorrhage due to fibrinolysis occurring with open-heart operations. J Thorac Cardiovasc Surg 46: 673-679, 1963

34) User HM, Nadler RB: Applications of FloSeal in nephron-sparing surgery. Urology 62: 342-343, 2003

35) van Dijk JH, Pes PL: Haemostasis in laparoscopic partial nephrectomy: current status. Minim Invasive Ther Allied Technol 16: 31-44, 2007

36) Voormolen JH, Ringers J, Bots GT, van der Heide A, Hermans J: Hemostatic agents: brain tissue reaction and effectiveness. A comparative animal study using collagen fleece and oxidized cellulose. Neurosurgery 20: 702-709, 1987

Address reprint requests to: Ingo Fiss, M.D., Department of Neurosurgery, Charité-University Medicine Berlin, Campus Benjamin Franklin, Hindenburgdamm 30, 12203 Berlin, Germany. e-mail: ingo.fiss@charite.de 